\title{
The clinical and economic implications of running a psychiatric outpatient facility without the continued presence of a psychiatrist
}

\begin{abstract}
Recruitment of psychiatrists to remote areas of a country is difficult. The consequence is seen clinically, patients do not get qualified care, and the facilities pay a lot for maintaining a rudimentary service. This is illustrated with data from an outpatient facility set up with one position as psychiatrist. The cost of maintaining the role of a psychiatrist by four stand-ins is the double of what one single doctor would cost, NOK $2,070,000$ versus NOK 950,000 ( NOK $100=\$ 12.50)$. The decisions made by four are difficult to streamline for patients at the facility and they encounter non-congruent treatment options.
\end{abstract}

Volume 5 Issue 5 - 2018

\author{
John Berg E \\ Faculty of Health Sciences, Oslo Metropolitan University, \\ Norway \\ Correspondence: John Berg E, Senior Consultant in \\ Psychiatry, Faculty of Health Sciences, Oslo Metropolitan \\ University, Norway, PO Box 4, St. Olavs plass, 0130 Oslo, Tel \\ 004767235000 ,Email jonn@pong.no
}

Received: October 9, 2018 | Published: October 16, 2018

\section{Introduction}

In a country with a social democratic health care system as in the Scandinavian countries, health care is supposed to cover all citizens at an equal level, regardless of where you live, age, sex, type of illness and personal wealth. The original model was the National Health Service in Britain. ${ }^{1}$ There are important clinical and economic reasons for this system to fail due to geographical distribution of services, especially within mental health. ${ }^{2-5}$

Urban and rural divide contribute to the difficulties described below. Psychologists, social workers, and nurses are employed in some psychiatric outpatient facilities where a psychiatrist is not present all the time. This would never be the case for an outpatient surgery. How may this come by?

Clinically

a. Recruitment of psychiatrists is not sufficient to cover all outpatient facilities. The reduction in the use of old style asylums as a reflection of the "law 180" reform in Italy demanded the deployment of outpatient facilities close to where people lived. These outnumbered the supply of psychiatrists.

b. A psychiatrist is not deemed important. A consequence of the lack of psychiatric expertise may be that the other health professions continue to treat patients without use of medications and without exclusion of medical conditions as the reason for a referral to the outpatient facility.

c. The role of the psychiatrist in the outpatient facility is one of controlling on-going medical treatment or instituting new if the psychotherapist deems it important.

d. Collaboration with GPs is deemed sufficient for the use and evaluation of psychotropic medications.

e. A long distance from university clinics and bigger cities increases the shortage of psychiatrists who find it unsatisfactorily to practice without colleagues. This is also relevant for other medical specialities.

f. Financially g. Positions as psychiatrists are divided between two to four colleagues covering all weeks of the year

h. Doctors in training in psychiatry are employed to cover some of the aspects needed, but their work does not count as part of specialization in psychiatry.

i. Legal requirements force the clinics to hire psychiatrists through a recruitment firm. The cost of this is illustrated below.

j. Only psychiatrists and psychologists can set up a private clinical practice as part of the National Health Care System.

\section{Materials}

One outpatient facility in Northern Norway is described as an example. The employees are psychologists, social workers and specialized nurses. There is one position for a fulltime psychiatrist. Four psychiatrist cover this position with one week each. None of them reside in Northern Norway. The outpatient facility is situated in a nearby building to the local somatic hospital. Some patients must travel for more than two hours to get to the facility. Weather conditions may be such that appointments must be cancelled at short notice. Stipulated production demand on each counsellor is three encounters with patients five days a week. They have regular pay regardless of production level. The psychiatrist has a production demand of six encounters per day. NOK $100=\$ 12.50$.

\section{Results}

Pay for a fulltime psychiatrist is NOK 950000 per year before tax. A part time psychiatrist through recruitment firms may get NOK 850 per hour worked, i.e. NOK $850 \times 40$ hours per week $x 45$ weeks per year $=$ NOK $1,530,000$. The psychiatrists get travel and accommodation covered by the employer. The recruitment firm asks a surcharge on the hourly salary of NOK 300 per hour, i.e. NOK 300x 40 hours x 45 weeks=NOK 540,000.

The increased administrative costs for the facility and the firm by having to hire four psychiatrists are not calculated.

\section{Discussion}

There are two challenges with recruitment of psychiatrists to 
remote areas of a country. The delivery of the service from the facility to the inhabitants of the catchment area depends on the presence of a psychiatrist. This is a requirement by law. Supplying psychiatric help to the public is a political aim sine qua non. Thus, the health administration must supply even if the cost of doing so is twice the cost of a resident fulltime psychiatrist, i.e. in this case NOK 2,070,000 versus NOK 950,000.

Ensuring continuity of care and equality of medication practices are difficult and often patients are met by differing treatment philosophies. As the four psychiatrists seldom meet, contrary to the situation in a bigger facility, the public may be bewildered. The decision whether to continue or stop a treatment series may differ between the therapists. ${ }^{6}$ It is cumbersome to contact one of the other therapists whenever prescriptions must be renewed or revised.

Psychiatric treatment with due emphasis on somatic and psychological factors is not as clear cut as in an eye clinic. Nonadequate quality treatment is harder to pinpoint within a psychiatric setting. Even more so since the single psychiatrist cannot guarantee that patients treated by other health professionals are sufficiently investigated and monitored. And, when the psychiatrist is not there because of holes in the work schedule.

Society pays a high price, here the double price for keeping an outpatient psychiatric facility running with insufficient psychiatric coverage.

\section{Acknowledgements}

None.

\section{Conflicts of interest}

Author declares that there is no conflict of interest.

\section{References}

1. Beveridge W. Full employment in a free society. 1ed. London: George Allen \& Unwin Ltd; 1944.

2. Cartwright WS, Kaple JM, editors. Economic costs, cost-effectiveness, financing, and community-based drug treatment. 1ed. NIDA research monograph series, editors. NIDA. National Institute on Drug Abuse. Rockville;1991(113):221.

3. Creed F. Cost effectiveness of day and inpatient psychiatric treatment: results of a randomised controlled trial. BMJ. 1997;314:1381-1385.

4. Jonsson B, Bebbington PE. What price depression? The cost of depression and the cost-effectiveness of pharmacological treatment. Br J Psychiatry. 1994;164(5):665-673.

5. Reinharz D, Lesage AD, Contandriopoulos AP. Cost-effectiveness analysis of psychiatric deinstitutionalization. Can J Psychiatry. 2000;45(6):533538.

6. Berg JE. Reluctance to change and end psychotherapy. Mental Illness. 2017;9:52-53. 